\title{
Prescribing Pattern and Drug Use in Ophthalmology Out Patient Department of Nepalgunj Medical College, Nepalgunj, Nepal
}

\author{
Dhami DB ${ }^{1}$, Thapa BB ${ }^{2}$, Neupane $\mathrm{GP}^{3}$
}

\begin{abstract}
Introduction: Monitoring, evaluation and modification of prescriptions of prescriber can be achieved by the study of prescribing pattern through prescription audit. WHO and INRUD have evolved standard drug use indicators to improve the overall drug use in developing nations like Nepal. Aims and objective: To describe the patterns of prescription and drug use at ophthalmology at outpatient department (OPD). Materials and methods: The study was conducted at Out Patient Department of ophthalmology at Nepalgunj Medical College, Nepalgunj. The data was collected from the patients who visited the OPD during the period from May to November 2017. Total 855 Prescriptions were audited and WHO drug prescribing and use indicators were analyzed. Results: The number of drugs per prescription varied from one to five with an average of 2.6. Majority of drug $97 \%$ was prescribed in brand name. The maximum (76\%) drugs were prescribed as topical form. Eye drops $64 \%$ were the most commonly prescribed followed by ointments $(12 \%)$, tablets (11\%), capsules ( $9 \%)$, syrups (3\%) and injections (1\%). Sixty percent lubricants were prescribed followed by anti-allergic and Anti-inflammatory (20\%) then antimicrobials $17 \%$, Mydriatric and cycloplegic $7 \%$. The dosage forms of the drugs were recorded for $92 \%$ and the frequency of administration was recorded for $96 \%$ of the prescriptions whereas duration of treatment was mentioned for $66 \%$ of the prescription. Conclusion : In the hospital setting drug utilization pattern must be monitored time to time to analyze their rational use, provide feedback and suggestion to the prescriber.
\end{abstract}

Key words: Generic name, prescribing pattern, WHO drug use indicators

\section{INTRODUCTION}

Drug utilization is defined as marketing, distribution, prescription and the use of drugs with special emphasis on the resultant medical, social and economic consequences ${ }^{1}$. In the hospital setting drug utilization pattern must be monitored time to analyze their rational use, provide feedback and suggestion to the prescriber ${ }^{2}$. WHO drug use indicator is used to evaluate the prescription pattern to promote rational use of drug $^{3}$ WHO and INRUD have evolved standard drug use indicators to improve the overall drug use in developing nations like Nepal ${ }^{4}$. Monitoring, evaluation and modification of prescriptions of prescriber can be achieved by the study of prescribing pattern through prescription audit ${ }^{5}$. Till date there is no study has been done on prescribing pattern in ophthalmic care in Western Nepal. The periodic auditing of the prescription helps to measure the impact of the prescribing pattern. So, the present study was done with the aim to study the drug use pattern in ophthalmology outpatient department and to evaluate the drug use for rationality.

1. Dr. Dabal Bahadur Dhami

2. Dr. Bikram B Thapa

3. Dr. Ganesh Prasad Neupane

Address for correspondence: Dr. Dabal Bahadur Dhami Department of Pharmacology Nepalgunj Medical College Chisapani, Banke, Nepal Email:drddhami@gmail.com

\section{Aims and objective}

To describe the patterns of prescription and drug use at ophthalmology at out-patient department (OPD)

\section{MATERIALS AND METHOD}

The study was conducted at Out Patient Department of Ophthalmology at Nepalgunj Medical College, Nepalgunj. Study was approved from Institutional Review Committee of Nepalgunj Medical College. The data was collected from the patients of all age groups of either sex, who visited the OPD during the period from May to November 2017. Patients on follow up and patients who were not prescribed any drug but undergo other interventional procedures were not included in the study. Patients who did not gave consent for study were also excluded. After taking the consent from patients or patient's relatives in case of minor, data were collected from the patient's OPD card in working proforma. Prescriptions of 855 patients who were treated during the course of the study were audited and WHO drug use indicators with parameter like drug route, dosage form, indications for which prescribed, average number of drugs per prescription, percentage of drugs prescribed by generic name and brand name and drugs prescribed from NLEM-2016,

\section{RESULT}

The total 855 prescriptions were analyzed. The number of drugs per prescription varied from one to five, three drug in $32.16 \%$ of prescription followed by two i.e.; $27.48 \%$ (Table -1 ) with an average of 2.6 (Table-II). 


\begin{tabular}{|l|c|c|}
\hline $\begin{array}{l}\text { Number of drug } \\
\text { per prescription }\end{array}$ & $\begin{array}{c}\text { Number of } \\
\text { prescription }\end{array}$ & Percentages \\
\hline One & 170 & 19.8 \\
\hline Two & 235 & 27.48 \\
\hline Three & 275 & 32.16 \\
\hline Four & 101 & 11.8 \\
\hline Five & 74 & 8.6 \\
\hline Total & 855 & 100 \\
\hline
\end{tabular}

Table I: Number of drug prescribed per prescription

Patients suffering from various ocular disorders attended the OPD during the study period (Figure 1). The most common disorders diagnosed were allergic eye diseases $28 \%$, dry eye $25 \%$ and Presbyopia $20 \%$ followed by viral eye infection, cataract, refractive error, pterygium,trauma and uveitis.

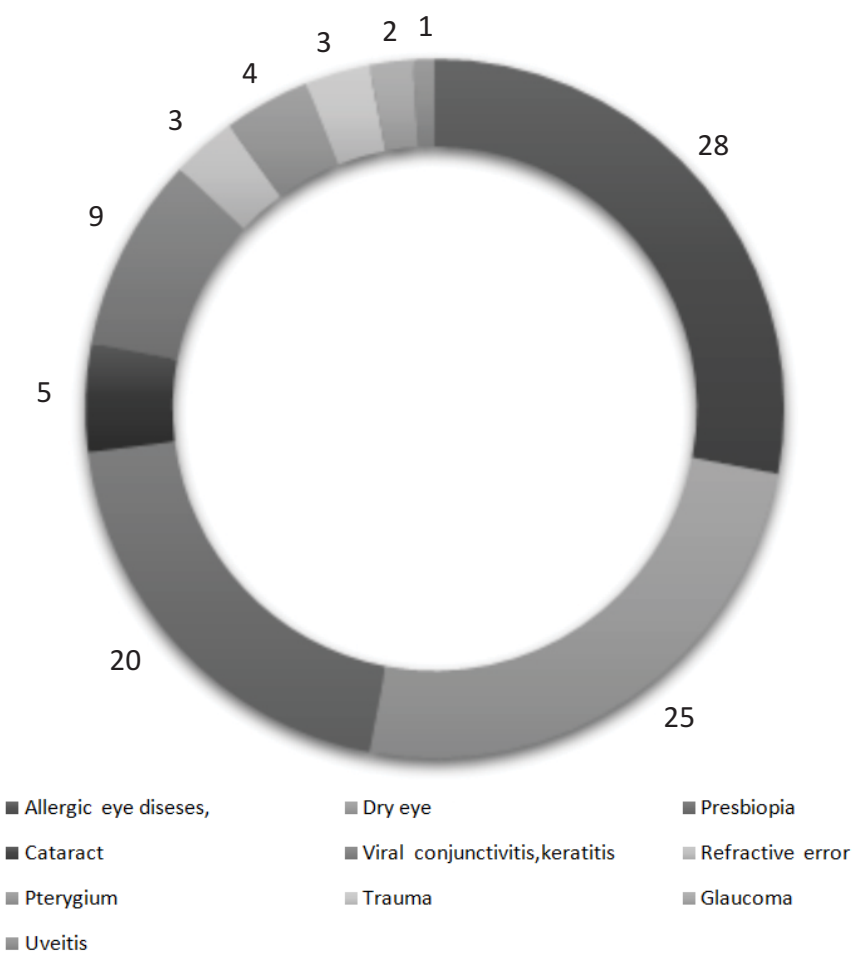

Figure 1: Occular diseases pattern

Seven different dosage forms were prescribed (Figure 2). Eye drops $64 \%$ were the most commonly prescribed followed by ointments (12\%), tablets (11\%), capsules $(9 \%)$, syrups (3\%) and injections (1\%). Five hundred and thirteen (60\%) lubricants were prescribed followed by anti-allergic and Antiinflammatory (20\%) then antimicrobials $17 \%$, Mydriatric and cycloplegic $7 \%$, mitotic $0.5 \%$ and others $2 \%$ of the total drugs prescribed (Figure-3).

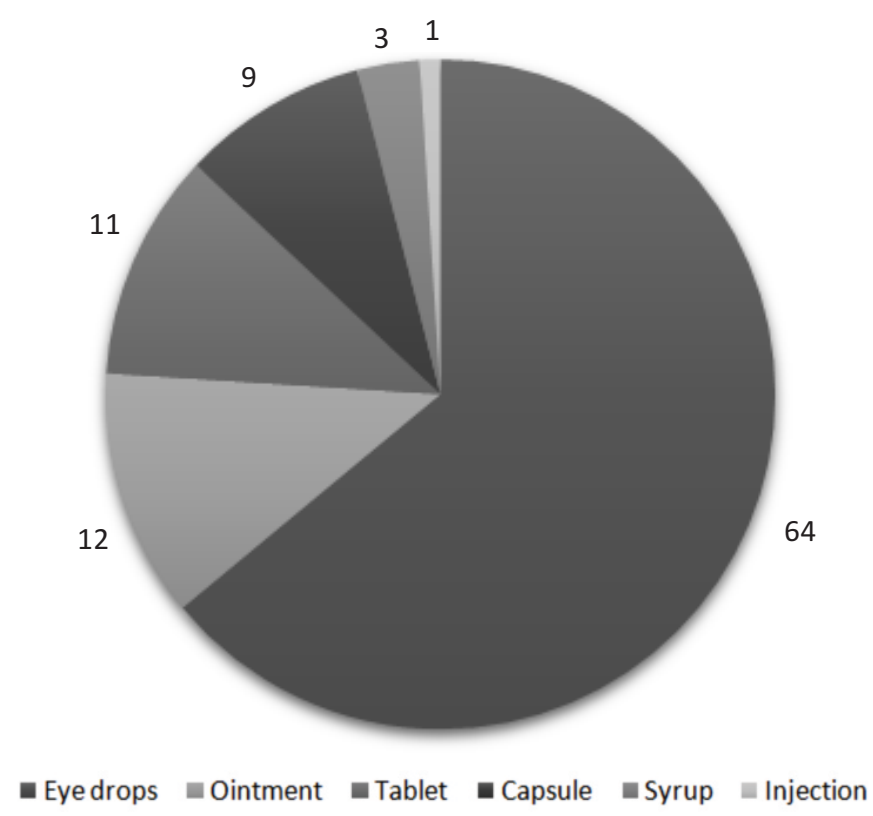

Figure 2: Formulation of prescription in percentage

Five hundred and thirteen (60\%) lubricants were prescribed followed by anti-allergic and Anti-inflammatory (20\%) then antimicrobials $17 \%$, Mydriatric and cycloplegic $7 \%$, mitotic $0.5 \%$ and others $2 \%$ of the total drugs prescribed (Figure- 3 )

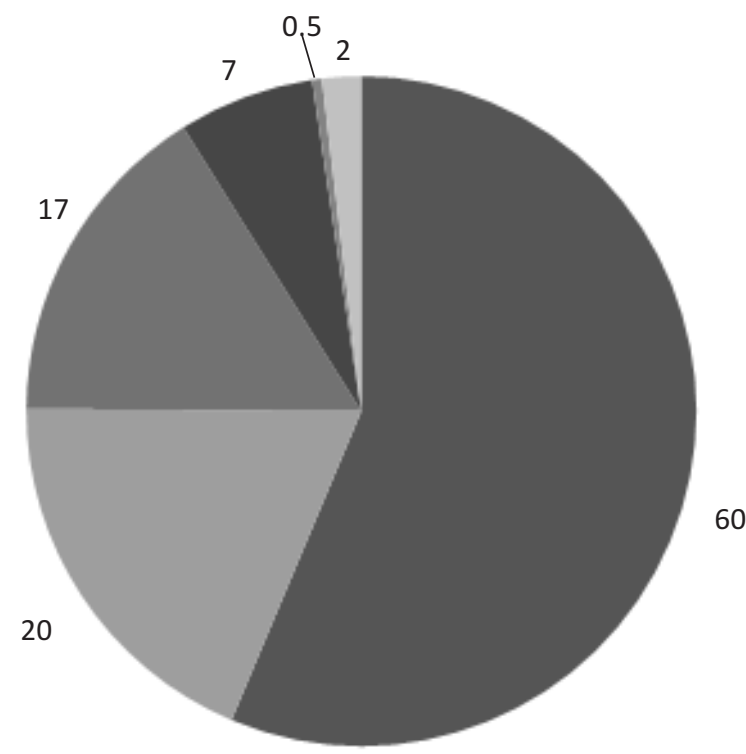

Lubricants

antimicrobials

Miotics
Anti-inflammatory \& ant allergic

Mydriatric/cycloplegic

nothers
Figure 3: Type of Medication prescribed 
The maximum number $650(76 \%)$ drugs were given for topical use in the form of eye drops $547(64 \%)$ and ointments 103 (12\%) followed by oral $188(22 \%)$ as tablets, capsules and syrup form (Table-II).

\begin{tabular}{|c|}
\hline Type of medication \\
\hline Drops 547(64\%) \\
\hline Carboxy methyl cellulose(Refresh tear, Relub) \\
\hline Ofloxacin-dexamethasone combination(OXOO-D \\
\hline Moxifloxacin (milflox, mosi) \\
\hline Ciprofloxacin(zoxan) \\
\hline Tobramycin (toba, ocutob) \\
\hline Acyclovir (occuvir) \\
\hline Natamycin (natoptic) \\
\hline Timolol (glucontim, iotim) \\
\hline Olopatadine( winolap or OPD-1) \\
\hline Cyclopentolate (cyclopent) \\
\hline Prednisolone (predmet) \\
\hline Fluromethalone (FML) or (floman) \\
\hline Flurbiprofen (FBN,Eyefen) \\
\hline Homotropine (homide, aurohom) \\
\hline Pilocarpine (pilocar) \\
\hline Sodium chromgolycate (allercrom) \\
\hline Hypromellose $\mathrm{NaCl}$ \\
\hline Ointment 103 (12\%) \\
\hline Ciprofloxacin (Zoxan) \\
\hline Tetracycline (occucycline) \\
\hline Chloramphenicol-dexamethasone (occupol-D) \\
\hline Chloramphenicol (occupol) \\
\hline Acyclovir(occuvir) \\
\hline Oral $188(22 \%)$ \\
\hline Ciprofloxacin (Zoxan) \\
\hline Ofloxacin (ZO) \\
\hline Ranitidine (aciloc) \\
\hline Prednisolone (cortilone) \\
\hline Flucloxacillin (Flupen) \\
\hline Codeine-paracetamol (codomol) \\
\hline
\end{tabular}

Table-II: Common therapeutic agents prescribed

The dosage forms of the drugs were recorded for $92 \%$ of the drugs and the frequency of administration was recorded for $96 \%$ of the prescriptions whereas duration of treatment was mentioned for $66 \%$. The analysis of the prescriptions showed that $97 \%$ of the prescriptions were written in the form of various trade names and that the generic names of the drugs were mentioned in $3 \%$ only (Table-II),

\begin{tabular}{|l|c|}
\hline Total number of prescription & 855 \\
\hline Average number of drug per prescription & 2.6 \\
\hline Percentage of dosage form recorded & $92 \%$ \\
\hline Percentage of frequency of therapy recorded & $96 \%$ \\
\hline Percentage of duration of therapy recorded & $66 \%$ \\
\hline $\begin{array}{l}\text { Percentage of encounters with an } \\
\text { antimicrobials prescribed }\end{array}$ & $60 \%$ \\
\hline $\begin{array}{l}\text { Percentage of encounters with an injection } \\
\text { prescribed }\end{array}$ & $2 \%$ \\
\hline Percentage of drug prescribed by generic name & $3 \%$ \\
\hline Percentage of drug prescribed by brand name & $97 \%$ \\
\hline
\end{tabular}

\section{Table-III Analysis of prescription (WHO core drug prescribing indicators)}

\section{DISCUSSION}

Drugs play crucial role in improving human health. Drug prescription form a very important point to contact between the doctor and patients. The degree of polypharmacy is measure by the average number of drugs per prescription. According to WHO the average number of drugs should be 1.6 to 1.8 per prescription. ${ }^{6}$ In this study the average number of drug per prescription was 2.6 which is very similar with the study done in India by Prajavati $\mathrm{V}$ et $\mathrm{al}^{8}{ }^{8}$ (2.23), Biswas et al $\mathrm{I}^{4}(3.0)$, Maniyar $Y$ et $a l^{9}$. (2.0), and Nehru $M$ et $a 1^{10}$ (1.8). Number of drugs per prescription should be kept to minimum otherwise prescribing more drugs would increases risk of drug interactions, adverse effects, increase treatment cost and increase prescribing error ${ }^{11}$.

Higher percentages of drug were prescribed as lubricants $60 \%$ followed by anti-allergic and Anti-inflammatory $20 \%$, this is due to prevalence of allergic eye disease and dry eye and environmental factors. So, lubricants, with anti-allergic and anti-inflammatory drugs prescribed are appropriate with prevalence of disease pattern.

Majority of drug were prescribed with topical routes $76 \%$ in the form of eye drops in $64 \%$ and ointments (12\%), followed by oral routes $22 \%$ in the form of tablets $(10 \%)$, capsules $(9 \%)$, syrups $(3 \%)$ and only $2 \%$ as injection. Similar pattern was shown in the study by Pooja Prajawal et al ${ }^{12} 67.65 \%$ eye drops, $11.66 \%$ ointment and $15.03 \%$ oral, by Nehru $M$ et $a^{10}{ }^{10}$, eye drops (66.18\%), followed by ointments (16\%), capsules (9.5\%), tablet $(6.57 \%)$, syrup $(0.73 \%)$, injection $(0.73 \%)$ and by Prajavati $V$ et al ${ }^{8} 75,34 \%$ eye drops, which strongly supports that the topical routes with eye drops and ointment has minimal adverse effects than systemic admisntration of drug.

In this study drug prescribed by generic name was very low $3 \%$ that is due to the frequent visit of the medical representatives in hospital setting could be the reason for under prescribing of the drugs by generic name. The percentage of drugs prescribed 
by brand name were $97 \%$, which is similar with previous study done by Prajavati V et al $^{8} 98.8 \%$, Pradeep R et al $^{13} 97.65 \%$, by Pooja P et al $^{12} 67.56 \%$ of brand name, which suggest popularity of brand names among the ophthalmologist and influence of pharmaceutical companies over prescriber. However, prescribing by brand name could result prescribing error because of similarity of many drugs with their spelling.

The analysis of the prescriptions showed that the dosage forms of the drugs were recorded for $92 \%$, frequency of administration was recorded $96 \%$ whereas duration of treatment was mentioned for $66 \%$. Which was very similar with the study by Pooja P et $\mathrm{al}^{12} 91 \%, 97 \%$, and by Maniyar $\mathrm{Y}$ et $\mathrm{al}^{9}$ was $69 \%$ and $99.88 \%, 94 \%$ and $57 \%$ respectively.

\section{CONCLUSION}

Excessive polypharmacy and prescribing in brand name due to high influences of pharmaceutical company over prescriber was quite common in Nepal which is not in WHO standard. In the hospital setting drug utilization pattern must be monitored time to analyze their rational use, provide feedback and suggestion to the prescriber. Concept of generic prescribing and continuous supervision and imparting education to the ophthalmologists about prescribing pattern should be initiated. There is a need to conduct similar studies in other departments and need to audit a large number of prescription on rational drug therapy for the benefits and safety of the patients.

\section{REFERENCES}

1. WHO. The selection of essential drugs: Report of a WHO expert committee. World Health Organ Tech Rep Ser. 1977;615:1-36.

2. Sarkar C,Das B, Sripathi H. drug prescribing pattern in dermatology in a teaching hospital in western Nepal. journal of Nepal Medical Association(JNMA), 2001:41:241-246.

3. Chapagain K, Pokharel R. Paranjape BD. Evaluation of Prescription Pattern and Rational Prescribing in Eastern Nepal .Journal of Nobel Medical College. Volume 5, Number 1, Issue 8, January-July 2016, 32-36.

4. Biswas NR, Jindal S, Siddiquei MM, Maini R. Patterns of prescription and drug use in ophthalmology in a Tertiary Hospital in Delhi. Br J Clin Pharmacol. 2001;51:267-9.

5. Nihar R. Biswas, Rajat S Biswas, Prem S.Pal,patterns of prescriptions and drug use in two tertiary hospitals in delhi .Indian J Physiol Pharmacol 2000; 44 (1): 109-112.

6. WHO, How to Investigate Drug Use in Health Facilities: Selected Drug Use indicators. Geneva WHO/DAP; 1993; 1:1-87

7. Government of Nepal, ministry of health, department of drug administration, national list of essential medicines Nepal (fifth revision) 2016; 1-37 ( Final NLEM 2016.pdf).

8. Prajapati $V$, Yadav AK, drug used in ophthalmology out patients departmet: A prospective study at tertiary care teaching hospital. Indian journal of pharmacy practice,2012:-5, issue 2:44-48
9. Maniyar Y, Bhixavatimath $P$, Akkone $V$. A drug utilization study in the ophthalmology department of a Medical College, Karnataka, India. J Clin Diagn Res. 2011;5:82-4.

10. Nehru M, Kohli K, Kapoor B, Sadhotra P, Chopra V, Sharma R. Drug utilization study in outpatient ophthalmology department of Government Medical College. JK Science. 2005;7:149-51.

11. Nies AS. Principles of therapeutics. In: Gilman AG, Rall TW, Nies AS, editors. The Pharmacological Basis of Therapeutics Eighth Edition. New York: Pergamon Press; 1990. pp. 62-83.

12. Pooja Prajawal, Mohandas Rai,Sharath kumar K,Srinivas Bhant U,Floyd Vernon D. Drug utilization pattern in ophthalmology department at a tertiary care hospital. Int. J. Pharma.2013;4(8);205-210.

13. Pradeep R. Jadhav, Vijay V.Moghe, and Yeshwant A. Deshmukh. Drug Utilization Study in Ophthalmology Outpatients at a Tertiary Care Teaching Hospital. ISRN Pharmacology. Volume 2013, Article ID 768792, 5 pages, http://dx.doi.org/10.1155/2013/768792. 